\title{
Processes through Which the Grandparents of a Child with Severe Motor and Intellectual Disabilities (SMID) May Become Involved in Raising the Child
}

\author{
Yuki Konoshima ${ }^{*}$, Junko Takemura ${ }^{2}$, Yuko Tomari ${ }^{3}$ \\ ${ }^{1}$ Department of Nursing Faculty of Health and Science, Nagoya Women's University, Aichi, Japan \\ ${ }^{2}$ Faculty of Nursing, Osaka Medical College, Osaka, Japan \\ ${ }^{3}$ Graduate School of Nursing, Kansai University of Social Welfare, Ako, Hyōgo, Japan \\ Email: *konoshim@nagoya-wu.ac.jp
}

How to cite this paper: Konoshima, Y., Takemura, J. and Tomari, Y. (2020) Processes through Which the Grandparents of a Child with Severe Motor and Intellectual Disabilities (SMID) May Become Involved in Raising the Child. Open Journal of Nursing, 10, 1251-1264.

https://doi.org/10.4236/ojn.2020.1012091

Received: November 20, 2020

Accepted: December 28, 2020

Published: December 31, 2020

Copyright ( 2020 by author(s) and Scientific Research Publishing Inc. This work is licensed under the Creative Commons Attribution International License (CC BY 4.0).

http://creativecommons.org/licenses/by/4.0/ (c) (i) Open Access

\begin{abstract}
In Japan, it is common practice to involve grandparents in the care of children with severe motor and intellectual disabilities (SMID), as it may be difficult for nuclear families to handle such children by themselves. This study aimed to explore and describe the process through which the grandparents of children with SMID may be involved in their upbringing. Data were obtained via semi-structured interviews with 13 grandparents who had a grandchild with SMID. The collected data were examined using Yasuhito Kinoshita's modified grounded theory approach. Altogether, 11 categories were identified from 29 themes. The results revealed two broad patterns concerning the nature of the grandparents' involvement and their definition of grandparenthood in the context of raising a grandchild with SMID. In one process, grandparents supported the child's family. They also learned to relate to the child and their family, despite experiencing a lack of responsiveness from the child initially. This ultimately resulted in them being inspired by their grandchild. In the other process, the grandparents left the care of their grandchild to the child's family and chose to monitor the child's welfare indirectly. In both the processes, the level of involvement was determined by the extent to which the family chose to ask grandparents for help. The study's findings can be used to identify the kind of support that grandparents of children with SMID require while highlighting the role of considering the needs and intentions of the children's families.
\end{abstract}

\section{Keywords}

Grandparents, Children, Severe Motor and Intellectual Disabilities, Support, 
Extended Family, Caregiving, Japan

\section{Introduction}

In Japan, there are approximately 29,000 children with severe motor and intellectual disabilities (SMID) [1]. Despite being severely disabled, many children with SMID live at home. However, living with such a child has a significant impact on the entire family. In particular, for the mother, caring for the child results in limited time for herself and she may not be able to share her feelings of being overburdened. When these mothers choose to express their feelings with someone, they often do so by talking with the child's grandparents [2]. Furthermore, when the extended family, including the grandparents, are asked for assistance, grandparents may act as care coordinators, assigning roles to family members that consider family dynamics, thereby mitigating the advent of problems [3].

Although some grandparents may desire to have a closer relationship and interact more with their grandchild, negative disability-related perceptions may hinder a better understanding of their grandchild's condition. As a result, they may not know how to interact with them [4]. Studies by Nojiri have verified that grandparents' understanding of their grandchild's disabilities progressed in a gradual upward spiral involving repeated explanations from the child's parents [5] [6]. This pattern may denote that, for grandparents, receiving information from their child about their grandchild's disabilities can help them understand their grandchild better. A review of studies on the roles of grandparents in families living with a child with SMID found that grandparents played a key role in influencing the mother, which in turn impacts the entire family. However, their roles were mainly related to supporting the mother and helping in caring for the disabled child's siblings [7]. Thus, it is conceivable that as grandparents become more considerate toward a disabled grandchild, they may become more involved in raising them as well. No studies have yet explored the actual process behind this phenomenon.

To consider the kind of support these grandparents may need, it is integral to look at how grandparents perceive their grandchild's disabilities and become more involved in raising the child. As a result, the purpose of this study was to explore and describe the processes through which the grandparents of a child with SMID may become involved in raising their grandchildren.

\section{Methods}

\subsection{Participants}

The target sample comprised grandparents who were not older than 75 years and had a grandchild of 15 years or younger with SMID. 


\subsection{Study Period}

The study took place from April to December 2018.

\subsection{Data Collection and Analysis}

We explained the purpose of the research to the facility managers of the facilities and hospitals in gifu prefecture, Japan. We recruited participants from the facilities that requested for the survey and gave us permission to conduct the interviews. Data were obtained by conducting semi-structured interviews for the research participants who agreed to be a part of the research. We asked the grandparents to talk freely in response to two questions:

1) Please talk about your involvement with your grandchild and with the grandchild's family from the time the child was born.

2) Please talk about what your grandchild's existence has meant for you.

For the analysis, we used Yasuhito Kinoshita's modified grounded theory approach (M-GTA) [8]. The interviews were recorded and transcribed. Following the M-GTA protocol, relevant excerpts from the transcription were identified that described the Analytically Focused Person, which, in this study, referred to "grandparents who had some involvement in raising a grandchild with SMID" and the Analytical Theme, which was "how they were involved with the child with SMID and with the child's family." Next, the significance of each of the identified excerpts was utilized to generate appropriately named themes (referred to as "gainen" (concepts) in the M-GTA). Themes were generated on a case-by-case basis and then refined by comparing the similarities and differences between them. Subsequently, relationships between themes were examined to generate relational themes. Once the categories were developed, a model highlighting the relationships among them (i.e., order and relative position in the process) was created. Based on this model, a storyline was created to further elucidate the relationships between the categories.

To ensure the reliability of the analytical process, it was performed under the supervision of an experienced qualitative researcher.

\subsection{Ethical Considerations}

The study was conducted with the approval of the Osaka Medical University Research Ethics Review Board (approval no. 1940). Participants were provided with an explanation of the study's purpose and methodology, assured that their anonymity would be protected and that participation in the interview was voluntary. We further explained that the study's results could be presented at a nursing conference.

\section{Results}

\subsection{Participants and Their Grandchildren}

The sample consisted of 13 grandparents (four grandfathers and nine grandmothers) in their $60 \mathrm{~s}$ and $70 \mathrm{~s}$. Specifically, three grandparents lived with their 
grandchild's family and 10 lived separately. Furthermore, six grandparents saw their grandchild almost daily and those who saw them less frequently did so twice or thrice a year. Lastly, four grandparents were employed.

The grandchildren consisted of nine girls and four boys between 6 and 13 years. Nine grandchildren needed medical care, including oral suctioning and tube feeding.

\subsection{Storyline, Categories, and Themes}

The interviews lasted from a minimum of 50 minutes to a maximum of $90 \mathrm{mi}-$ nutes. Altogether, 11 categories were identified from 29 themes. Based on the model presented in Figure 1, the following storylines used the categories to describe the processes that the grandparents experienced, which accounted for their involvement in the care of their disabled grandchildren. In the storylines, categories are indicated in underlined bold italics, and in the explanations of the categories that follow, the themes are in bold and quotations from participants are in italics. The quotations are followed by either " $g m$ " or " $g f$ " to indicate whether the speaker was a grandmother or a grandfather.

1) The storylines

The analysis signified that two processes yielded varying levels of grandparent involvement with regard to the upbringing of a grandchild with SMID. In the first process, after the grandchild's birth, the grandparents were initially at a loss as to what to do, due to the anxiety of not knowing what was wrong with the child. However, they started to think that as grandparents, they first wanted to assist the mother. Then, they began to feel that even if they were not able to hold their grandchild because of the severity of the child's condition, they would be happy just to look at their grandchild. These grandparents stayed involved by supporting the child's family indirectly, but after some time, they began to feel that they wanted to be more directly involved in providing care for their grandchild, and it took them time to learn how to do so. However, seeing how much medical care the child needed, they became more concerned about the child $s$ care in the future. When opportunities for direct contact with their grandchild increased, they began to feel that they were learning to relate to the child despite the child s unresponsiveness and, eventually, the existence of their disabled grandchild made their life worth living.

In the second process, at the time of their grandchild's birth, these grandparents were at a loss as to what to do due to the anxiety of not knowing what was wrong with the child (similar to process 1 ). Seeing that the child's family was more or less managing to get along in their daily lives, they decided to not get involved in caring for the child because the family did not want to depend on them for help. When they visited their grandchild, they did not get involved in the child s care but observed them from a distance. However, the grandparents became more concerned about the child s care in the future. For these grandparents, involvement in raising the child meant facilitating the welfare of the child 


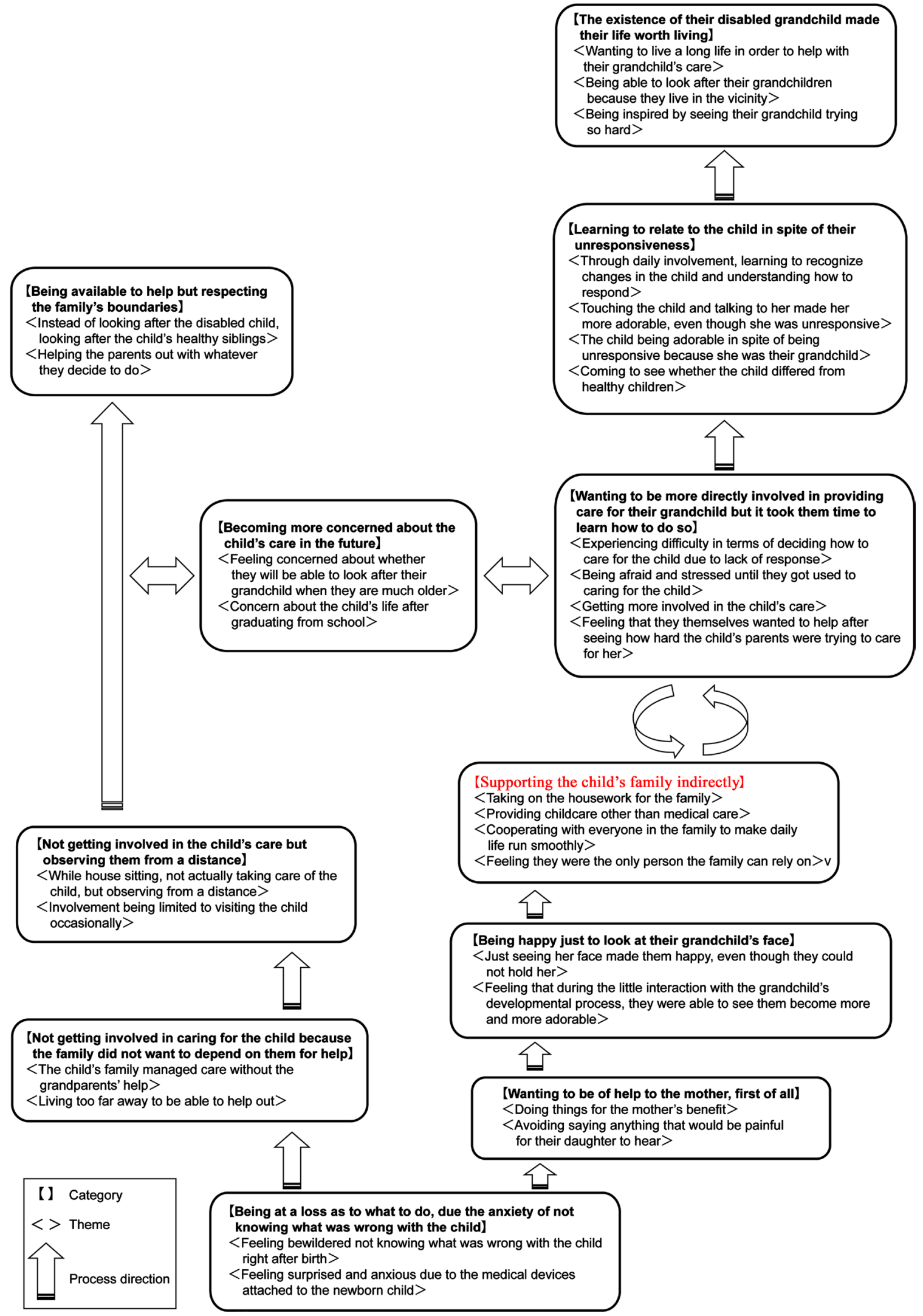

Figure 1. Processes determining grandparents' involvement in the care of a grandchild with severe motor and intellectual disabilities (SMID). 
and the child's family and being available to help but respecting the family's boundaries.

2) The generation of themes and categories

Table 1 shows the 29 themes and 11 categories that define the two processes based on the grandparents' experience. These processes determined the nature of the grandparents' involvement in the care of their disabled grandchild.

Category 1: Being at a loss regarding the way forward, due to the anxiety of not knowing what was wrong with the child

This category was derived from two themes indicating that the grandparent felt uninformed because they had no point of reference.

Feeling bewildered about what was wrong with the child right after birth

I was told by the doctor that the newborn baby was in a critical condition, but we could not understand what was happening. After that, I do not remember anything. (gm)

Feeling surprised and anxious due to the medical devices attached to the newborn child

They saved the baby's life, but I was surprised to be told by the doctor that she would need an artificial respirator to breathe. I was very worried about whether she would live. (gm)

\section{Category 2: Primarily wanting to be of help to the mother}

This category was derived from two themes indicating that they tried to find things to do that would benefit the mother.

Doing things for the mother's benefit

I would keep my daughter company when she nursed the baby. (gm)

Avoiding saying anything that would be painful for their daughter to hear

I think the experience was more challenging for my daughter. She rarely asked me about the baby, and I never asked her anything. (gm)

\section{Category 3: Being happy just to look at their grandchild}

This category was derived from themes that indicated that they felt happy that their grandchild was alive and they could see the child.

Just looking at their grandchild made them happy, even though they could not hold him/her

While she was in hospital, I went to see her face every day. Although I could not hold her yet, just being able to see her face was such a relief. It made me happy. (gm)

Being able to witness their grandchild's developmental process to some extent made the child seem more endearing

Although during visitation times, I was not able to hold my grandchild. However, it was apparent that little by little, she was getting bigger, and becoming more and more adorable. (gm)

Category 4: Supporting the child s family indirectly

This category was derived from the four themes displaying how the grandparent assumed certain responsibilities that their family was too busy to fulfill. 
Taking on the housework for the family

I left the child s care to my daughter and her husband and focused on doing housework so my daughter could spend more time with the child. (gm)

Providing childcare other than medical care

My daughter took care of almost all the medical care. I changed the childs diaper and got her medications ready to take. (gm)

Cooperating with everyone in the family to make daily life run smoothly Everyone helps out with medical care and things like changing diapers. We cooperate to get everything done. (gf)

Feeling they were the only person who could help the family

When they took the child out, I always went along with them. I tried to help the family out because I felt that there was no one else besides me who could. (gm)

Category 5: Wanted to be more directly involved in providing care for their grandchild, but it took them time to learn how to do so

This category was defined by the following four themes indicating the desire to care for the child, but that it took time to acquire the skill.

It was difficult to decide how to care for the child due to unresponsiveness

I get frustrated because I cannot understand clearly what the child is saying, so I do not know what she wants me to do. (gm)

Being afraid and stressed until they got used to caring for the child

When I stayed home with the child so my daughter could go out, I would get stressed about whether I could take care of the child alone, but gradually I got used to it. (gf)

Getting more involved in the child's care

It was after her siblings were born that I got more involved in taking care of my disabled grandchild. I stayed at my son's home overnight to take care of her. (gm)

It was when my grandchild began going to an elementary school that I had more opportunities to interact with her. My involvement with her grew as a result of me picking and dropping her at school. (gm)

Feeling that they wanted to help after seeing the child's parents struggle My son and his wife tried to do everything they could for their child. Witnessing that, I, too felt I wanted to do whatever I could to help her. (gm)

Category 6: Being concerned about the child's care in the future, as the child gets older

This category was defined by two themes denoting the grandparents' concern in relation to their disabled grandchild's future. Even as an adult, they might never be able to live independently.

Feeling concerned about taking care of their grandchild when they are much older

Because I am still healthy, I feel like I want to look after her. However, I worry about how long we will be able to look after her when we get to be very old. (gm) 
Table 1. Categories and themes describing the process determining grandparents' involvement in the care of a grandchild with severe motor and intellectual disabilities (SMID).

Category Themes

1. Being at a loss as to what to do, due to the anxiety Feeling bewildered about was wrong with the child right after birth of not knowing what was wrong with the child

Feeling surprised and anxious due to the medical devices attached to the newborn child

2. Primarily wanting to be of help to the mother Doing things for the mother's benefit

Avoiding saying anything that would be painful for their daughter to hear

3. Being happy just to look at their grandchild

Just seeing their grandchild made them happy, even though they couldn't hold her/him

Being able to witness their grandchild's developmental process to some extent made the child seem endearing

4. Supporting the child's family indirectly

Taking on the housework for the family

Providing childcare other than medical care

Cooperating with everyone in the family to make daily life run smoothly

Feeling they were the only person the family had to help them out

5. Wanted to be more directly involved in providing Experiencing difficulties in deciding how to care for the child for due to their lack of care for their grandchild but it took them time to responsiveness

learn how to do so

Being afraid and stressed until they got used to caring for the child

Getting increasingly involved in the child's care

Feeling that they themselves wanted to help after seeing how hard the child's parents were trying to care for her/him

6. Being concerned about the child's future care

Feeling concerned about taking care of their grandchild when they are much older

Concern about the child's life after graduating from school

7. Learning to relate to the child despite the child's unresponsiveness

Through daily involvement, learning to recognize changes in the child and understanding how to respond

Touching the child and talking to her made her seem endearing, even though she was unresponsive

The child seemed adorable despite being unresponsive because she was their grandchild

Realizing that the child differed from healthy children

8. The existence of their disabled grandchild made Wanting to live a long life to help with their grandchild's care their life worth living

Being able to look after their grandchildren because they live in the vicinity

Being inspired by their grandchild's efforts

9. Not getting involved in caring for the child because the family did not want to depend on them for help

The family managed the child's care without the grandparents' help

Living too far away to be able to help out

10. Not getting involved in the child's care but observing the child from a distance

Child-minding and observing the child from a distance

Involvement being limited to visiting the child occasionally

11. Being available to help but respecting the family's boundaries

Helping the parents out with whatever they decide to do

Instead of looking after the disabled child, looking after the child's healthy siblings 
Concern about the child's life after graduating from school

While she is going to school, things will continue to be fine because her teachers understand her well. However, I worry about whether she will be able to find such understanding people after she graduates. (gf)

Category 7: Learning to relate to the child despite their unresponsiveness

This category was defined by four themes that represented their ability to recognize changes in the child and understand their feelings, resulting in communication.

Through daily involvement, harnessing the ability to recognize changes in the child and understanding how to respond

As I am with my grandchild every day, I can see her process of development, but if I were only to see her occasionally, I do not think I would be able to see that. (gm)

Touching the child and talking to her made her seem endearing, even though she was unresponsive

I made it a point to caress her because I think it is important for a child to be touched from when they are small. Even though she does not respond, I think caressing must be very good for her. (gm)

The child seemed adorable despite being unresponsive

Because she is my grandchild, if she were to answer when I say something to her, I would be so happy. In any case, because she's my grandchild, she is, of course, adorable. (gf)

Realizing that the child differed from healthy children

When she came home, I do not think she differed from a normal child. However, as she grew older, I could see that her movements were slow in comparison to other children. ( $\mathrm{gm})$

Category 8: The existence of their disabled grandchild made their life worth living

This category was derived from three themes indicating that they began to feel that their disabled grandchild was irreplaceable and their existence made their life worth living.

Wanting to live a long life to help with their grandchild's care

Together with my daughter, we are trying to do the best we can. I do feel that I cannot afford to get sick and I have to live a long life. (gm).

Being able to look after their grandchildren because they live in the vicinity

If my grandchild was not sick, I do not think the family would be living near me. Being able to see the faces of my grandchildren makes it all worthwhile. (gf)

Being inspired by their grandchild's efforts

It seems to me that my grandchild is trying so hard to do the best she can. When I see her, I think that I, too, should be trying to live life the best way I can. (gf)

Category 9: Not getting involved in caring for their grandchild because 


\section{the family did not want to depend on their help}

This category was derived from two themes that indicated that the grandparents did not try to get more involved in raising the child because the child's family was independent and did not want to rely on the grandparents for help.

The child's family managing without the grandparents' help

My daughter and her husband never asked for my help with raising the child. When they have some kind of problem, it seems that they gather information, discuss the problem with their friends, and decide what to do. (gf)

Living too far away to be able to help out

Although I d like to do what I could for my daughter's family, because of the distance I cannot get there right away. I call them, but sometimes they do not answer. $(\mathrm{gm})$

Category 10: Not getting involved in the child s care but observing them from a distance

This category was derived from two themes that showed that the grandparents were not directly involved in the care of the child. Their involvement consisted of monitoring the welfare of the child from a distance.

\section{Child-minding and observing the child from a distance}

When my daughter goes out, she asks me to look after the children. When I am there, I do not do anything with the child except to just take a look at her once in a while $(g f)$.

\section{Limited involvement}

When the child goes for respite care at the hospital, I go along with the family. Afterward, I come back with them and help with chores. That is the only time I see my grandchild. (gm)

Category 11: Being available to help but respecting the family's boundaries

This category was derived from two themes showing that the grandparents cared for their grandchild but maintained distance to respect the child's family's boundaries.

\section{Helping the parents out with whatever they decide to do}

I try not to interfere much in the affairs of my son and his wife. Whatever they decide to do, I try to be helpful. ( $g f$ )

Instead of looking after the disabled child, taking responsibility for healthy siblings

The child's siblings talk to me because they are healthy. As a result, I, more or less, spend more time looking after them. (gf)

\section{Discussion}

\subsection{Characteristics of Grandparents' Involvement in Raising Grandchildren with SMID}

The results showed that there were two ways in which the grandparents in this study were involved in the upbringing of a grandchild with SMID: some were 
actively involved in providing the family with general support, and the others were not actively involved.

Regarding both levels of involvement, grandparents shared the same initial experience right after the child's birth. They felt lost because of the anxiety related to not knowing what was wrong with the child. However, the results suggested that, subsequently, differences arose depending on whether they were able to act on the feelings of wanting to help the mother, whether the child's family asked for the grandparents' help, and whether the family indicated that they did not want to rely on the grandparents for help.

The results established that when these grandparents were at a loss due to the anxiety of not knowing what was wrong with the child or when they wanted to be actively involved in caring for the child, they had to devise unique ways to be helpful, given the situational barriers arising from their grandchild's disabilities. When a child is healthy, aside from the father, the mother would probably turn to the grandparents for help with childcare. Moreover, studies suggest that when parents need childcare related assistance, it is usually related to parenting advice. Hence, a grandparent's advice based on their parenting experience would be a significant source of support as compared to direct help [9] [10]. However, when a child is severely ill or disabled, there may not be many occasions wherein a grandparent's child-raising experience would be useful. Nevertheless, by involving themselves in supporting the child's family and learning ways in which they could assist with the child's care, some of these grandparents discovered ways to utilize their childcare experience. Another characteristic of this level of involvement would be that these grandparents were willing to learn how to take care of their grandchild after the child's parents had mastered the caregiving process.

Results also signify that, in both processes, as the child got older, the grandparents were concerned about the future of the child. These concerns would be different for a healthy grandchild and a disabled one. When a child is born without a severe illness or disability, the family may need the grandparents' support when the child is an infant, but as the child gets older, it can be assumed that the family will require less assistance as the child becomes more independent. Consequently, grandparents' involvement naturally evolves from childcare duties to playing with the child. However, children with SMID need long-term care, and it is normal for them to require medical care throughout their lives, given that there is no prospect of being fully cured, and they are prone to develop complications and secondary disabilities [11]. As mothers of disabled children might be concerned about their child's future as well, such concerns were assumed to be an effect of caring for a child with a disability. The feeling of attachment was similar between the grandparents of healthy as well as disabled children.

Overall, the results suggested that the ways in which these grandparents were involved in the care of a grandchild with SMID differed depending on whether the child's family asked for their help or, in contrast, tried not to rely on them. 
This evidence suggests that when a grandchild is disabled, the grandparents must establish, early on, the extent to which the family wants them to be involved in helping to raise the child.

\subsection{The Evolution of Grandparenthood for Grandparents of Children with SMID}

Grandparenthood refers to "what it means to become a grandparent, be a grandparent, or act like a grandparent and the types of grandparents there are, are expressions of the relationships each grandparent makes" [12]. The study's findings showed that two processes concerning the grandchildren with SMID and the children's families defined grandparenthood for the grandparents.

First, when the child was born, these grandparents were at a loss as to what they should do, but some became involved in helping the children's families. With the parent's help, they tried to understand the nature of their grandchild's disability, and by caring for the child they could reach a point where they felt like they could relate to them. During this process, for a short time after the child's birth, they had been unable to find a role to play, suggesting that they were unsure of what grandparenthood meant in this situation. However, as they observed how the parents interacted with the children and after engaging with the children themselves, they started to feel closer to them. In particular, grandparents with unresponsive grandchildren explored numerous ways to interact with them, and learned to recognize small changes in their symptoms and differences in their facial expressions. These experiences enabled them to overcome the feeling of being distant from the child. This process could be characterized as one in which grandparents' relationships with their disabled grandchildren evolved by interacting with the child's family rather than by interacting with the child alone. For these grandparents, grandparenthood was related to a direct involvement in the upbringing of their disabled grandchildren.

In the second process as well, the grandparents were at a loss when their disabled grandchildren were born. It can be assumed that they experienced uncertainty regarding what grandparenthood meant in such a situation. However, in contrast to the first process, these grandparents had fewer occasions to directly interact with their grandchildren because the children's families were more independent. Despite not being directly involved in the care of their grandchild, these grandparents still felt concerned about the child's future, suggesting that, for them, grandparenthood entailed keeping a watchful eye on the welfare of the child and the child's family. Likewise, they were available to assist the family when asked. For them, grandparenthood was defined by a level of involvement that was respectful of the child's family boundaries.

In both the processes, immediately after the disabled child's birth, the grandparents were unsure of the status and nature of their role. The results suggested that the concept of grandparenthood for these grandparents varied due to differing expectations among the disabled children's families regarding the grand- 
parents' level of involvement in childcare.

In Japan, it is expected that grandparents will help with childcare. There are also several different views on what the ideal family with children should be like. For grandparents helping families care for a child with SMID, families may have differing expectations from their family life, so grandparents' involvement would differ accordingly. Therefore, support services for grandparents of children living with SMID must take into account the needs and intentions of the respective families.

\section{Conclusion}

This study revealed that the process that determined the level of grandparent involvement in caring for a grandchild with SMID consisted of two patterns. For both patterns, after the child's birth, the process began with the grandparents feeling anxious about their inability to comprehend the child's condition. Subsequently, two separate processes emerged. In one process, the grandparents provided the child's family with general support through which they learned to relate to the child despite the child's unresponsiveness, which ultimately led to them being inspired by their disabled grandchild. Alternatively, some grandparents left the care of their grandchild to the child's family, ultimately choosing to monitor the welfare of the child and the family while respecting their boundaries.

\section{Limitations}

The participants in this study seemed to be supportive of children with severe physical and mental disabilities. Since all the participants had a positive view of disability, the study does not explore the role of grandparents who might not have a positive and accepting approach towards disability. This could be a limitation of the current study.

\section{Acknowledgements}

We sincerely thank all the grandparents who agreed to participate in this study, as well as everyone at the facilities and medical institutions who introduced us to potential participants.

\section{Conflicts of Interest}

The authors declare no conflicts of interest regarding the publication of this paper.

\section{References}

[1] Ministry of Health, Labour and Welfare (2015) Support for Children with Disabilities. (in Japanese)

https://www.mhlw.go.jp/file/05-Shingikai-12601000-Seisakutoukatsukan-Sanjikans hitsu Shakaihoshoutantou/0000096740.pdf 
[2] Yamamoto, M. (2011) Mothers Who Not Voice their Toilsomeness: How Nurses of Severely Retarded Children Observe Such Mothers' Circumstances and Reach Out to Help. Journal of the Japanese Academy of Human Care Science, 4, 19-27. (in Japanese)

[3] Friedman, M. (1998) Family Nursing: Theory and Assessment. Part II Family Health Assessment. In: Chapter 12 Family Role Structure, Herusu Shuppan, Tokyo. (in Japanese)

[4] Konno, K. (2003) Helping Grandparents with Handicapped Grandchildren: Survey and Interview Research. Bulletin of the Center for Educational Research and Practice, Faculty of Education and Human Studies, Akita University, 25, 39-52. (in Japanese)

[5] Nojiri, E. (2012) Factors Encouraging Acceptance of Children's Disabilities by Grandparents. Japanese Association of Communication Disorders, 29, 1-8. (in Japanese)

[6] Nojiri, E. (2013) Factors Encouraging Acceptance of Children's Disabilities Grandparents. Japanese Association of Communication Disorders, 30, 9-17. (in Japanese)

[7] Konoshima, M. and Tomari, Y. (2018) The Literature Review on the Functions of Grandparents in Family Studies of Children with Severe Motor Intellectual Disabilities. Osaka Medical College Journal of Nursing Research, 8, 66-72. (in Japanese)

[8] Kinoshita, Y. (2007) Live Lectures on Everything about the Modified Grounded Theory Approach (M-GTA): A Practical Qualitative Research Method. In: Chapter 1: The M-GTA Analytical Technique. Tokyo. (in Japanese)

[9] Hayashi, S., et al. (2000) Grandmothers' Expected Role in Rearing a Child: From Research on the Actual Conditions of the Members of Kagawaken Boshi Aiiku Kai (the Kagawa Association of Assisting Mothers in Fostering Children (KAAMFC). Nursing Journal of Kagawa Medical University, 4, 83-89. (in Japanese)

[10] Soyama, S., Yoshida, K. and Yoneda, M. (2015) Relationship between the Experience of Raising Children among Grandmothers and Attitudes toward Raising their Grandchildren. Journal of Japan Society of Nursing Research, 38, 139-150. (in Japanese)

[11] Miyazaki, S. and Matsumoto, A. (Eds) (2007) Medical Care and Support for People with Severe Mental and Physical Disabilities. In: Chapter 1 Introduction. Kyoto. (in Japanese)

[12] Onodera, R. (2004) Depictions of Grandparents in Children's Picture Books. The Journal of Educational Sociology, 75, 5-23. (in Japanese) 